\title{
O desenvolvimento da TV no Nordeste: um estudo sobre o início da televisão no Rio Grande do Norte
}

\author{
Valquiria Aparecida Passos KNEIPP ${ }^{1}$ \\ Francisco das Chagas SALES JÚNIOR ${ }^{2}$
}

\begin{abstract}
Resumo:
Quando surgiu no Brasil, a televisão se concentrava no eixo Rio-São Paulo, mas com os avanços tecnológicos e o aumento na produção de televisores, as transmissoras de TV foram se espalhando pelo país. Observamos que no Nordeste esse processo levou mais tempo do que em outras regiões. Portanto, o objetivo deste artigo é investigar a implantação das emissoras nas capitais nordestinas, tendo como referência a chegada da TV no Rio Grande do Norte. Para alcançar o objetivo da pesquisa, contamos com os conceitos de Williams (2016) e Jost (2004) sobre a televisão; com as contribuições de Machado (2000), Rezende (2000) e Mattos (1990) sobre a trajetória da TV no Brasil; e de Kneipp (2017) sobre o Rio Grande do Norte. Consideramos que a distribuição de concessões de TV no Rio Grande do Norte se desenvolveu com base em critérios políticos, mas agora apresenta uma nova configuração, com a divisão entre grupos empresariais e políticos.
\end{abstract}

Palavras-chave: História da mídia. Televisão. Regionalização. Rio Grande do Norte.

\section{The development of TV in the Northeast: a study about the beginning of television in Rio Grande do Norte}

\begin{abstract}
:
When it appeared in Brazil, television was concentrated on the Rio-São Paulo axis, but with technological advances and the increase in television production, TV broadcasters were spreading throughout the country. We observed that in the Northeast this process took longer than in other regions. Therefore, the aim of this article is to investigate the deployment of broadcasters in the northeastern capitals, with reference to the arrival of TV in Rio Grande do Norte. To achieve the research objective, we rely on the concepts of Williams (2016) and Jost (2004) about television; with the contributions of Machado (2000), Rezende (2000) and Mattos (1990) on the trajectory of TV in Brazil; and Kneipp (2017) over Rio Grande do Norte. We consider that the distribution of TV concessions in Rio Grande do Norte was developed based on political criteria, but now presents a new configuration, with the division between business and political groups.
\end{abstract}

Keywords: History of the media. Television. Regionalization. Large northern river.

\section{El desarrollo de la televisión en el noreste: un estudio sobre el comienzo de la televisión en Rio Grande do Norte}

\footnotetext{
${ }^{1}$ Doutora em Comunicação pela Universidade de São Paulo (USP), professora do Departamento de Comunicação e do Programa de Pós-Graduação em Estudos da Mídia da Universidade Federal do Rio Grande do Norte.E-mail: valquiriakneipp@yahoo.com.br

${ }^{2}$ Mestre em Estudos da Mídia. Graduação em Jornalismo pela UFRN. Trabalha na TV Assembleia RN. E-mail: jornalismo_junior@yahoo.com.br
} 


\section{Resumen:}

Cuando apareció en Brasil, la televisión se concentró en el eje Río-São Paulo, pero con los avances tecnológicos y el aumento de la producción televisiva, las emisoras de televisión se extendieron por todo el país. Observamos que en el noreste este proceso tomó más tiempo que en otras regiones. Por lo tanto, el objetivo de este documento es investigar el despliegue de emisoras en las capitales del noreste, con referencia a la llegada de la televisión a Rio Grande do Norte. Para lograr el objetivo de investigación, confiamos en los conceptos de Williams (2016) y Jost (2004) sobre televisión; con las contribuciones de Machado (2000), Rezende (2000) y Mattos (1990) sobre la trayectoria de la televisión en Brasil; y Kneipp (2017) sobre Rio Grande do Norte. Consideramos que la distribución de concesiones de TV en Rio Grande do Norte se desarrolló con base en criterios políticos, pero ahora presenta una nueva configuración, con la división entre los negocios y los grupos políticos.

Palabras clave: Historia de los médios. Televisión. Regionalización. Río Grande del Norte.

\section{Introdução}

Apesar dos avanços tecnológicos vivenciados nos últimos tempos e a avalanche de informações e novidades disponibilizadas pela internet, a televisão continua sendo considerada um dos veículos de comunicação mais poderosos do mundo (BRASIL, 2016). A TV é ao mesmo tempo a principal fonte de informação e diversão para o povo brasileiro. Isso se deve ao fato de conseguir chegar aos lugares mais remotos de um país com dimensões continentais, como é o caso do Brasil.

Por isso, este estudo pretende compreender a chegada da televisão no Brasil, em especial no nordeste brasileiro, tendo como foco a implantação das emissoras de TV no estado do Rio Grande do Norte. O objetivo é entender como ocorreu esse processo, dentro do contexto histórico e social da região.

Supõe-se, levando em consideração os estudos sobre a história da mídia, que a implantação das estações de televisão no Nordeste aconteceu com certo atraso, em relação a outras partes do país e ao ano de implantação da própria televisão brasileira. A instalação da primeira emissora nordestina foi somente no início da década de 1960. Acredita-se que isso se deve, em grande parte, à falta de investimentos e de interesse político para o desenvolvimento da televisão na região.

Esta pesquisa constituiu-se em um estudo descritivo e analítico, tendo como base inicial a pesquisa bibliográfica, que consiste em um "conjunto de procedimentos para identificar, selecionar, localizar e obter documentos de interesse" (STUMPF, 2005, p. 54). Além disso, foram buscados documentos de regulamentação legal da televisão no Brasil e também os sites de todas as emissoras pesquisadas e dos órgãos governamentais relacionados com o objeto de estudo.

O aporte conceitual e teórico sobre a televisão de maneira geral compõe-se do clássico estudo de Williams (2016) e segue com referenciais como Jost (2004) e Bourdieu 
(1997). Outras contribuições como Machado (2000), Rezende (2000) e Mattos (1990) auxiliam na compreensão da trajetória da TV no Brasil e, também, o estudo mais específico de Kneipp (2017) sobre o Rio Grande do Norte.

\title{
A TV no Brasil
}

A televisão chegou ao Brasil, em 1950, por iniciativa do empresário Assis Chateaubriand, com a criação da PRF 3 TV Difusora, que depois passaria a se chamar TV Tupi, pioneira da América do Sul (MATTOS, 1997). Isso numa época em que transmitir som e imagem era uma novidade cara. Receber o sinal da televisão, então, era algo acessível a poucas pessoas.

Com o tempo e o crescimento da produção, o preço dos aparelhos foi se tornando mais acessível e as emissoras foram sendo instaladas em outros estados, deixando de se concentrar apenas no eixo Rio-São Paulo (MATTOS, 2010). É nesse contexto que a televisão brasileira vai ganhando elementos regionais e as redes de emissoras nacionais vão sendo formadas.

Bazi (2001) argumenta que a televisão regional é aquela que retransmite seu sinal a uma determinada região, delimitada geograficamente, e que tenha a programação voltada para ela mesma, sem perder o contexto global. Dentro do campo da comunicação, a televisão regionalizada vai ser mais um elemento dentro do processo de emissão e recepção.

\begin{abstract}
As emissoras regionais fornecem aos telespectadores, por meio da união da programação do regional e nacional, retratar os assuntos locais e ao mesmo tempo proporcionam acompanhar o que ocorre no país e no mundo. Se uma pessoa desejar assistir às "cores locais", basta sintonizar os programas gerados pelas emissoras regionais; se optar em saber o que acontece em outro lugar assiste aos programas da rede a qual está afiliada (BAZI, 2016, p. 23).
\end{abstract}

Ao buscar um conceito para a televisão tradicional, exibida em sinal aberto, Machado (2000) chama a atenção para o quanto é amplo o termo e para as possibilidades de produção, distribuição e consumo de imagens e sons eletrônicos:

Compreende desde aquilo que ocorre nas grandes redes comerciais, estatais e intermediários, sejam elas nacionais ou internacionais, abertas ou pagas, até o que acontece nas pequenas emissoras locais de baixo alcance, ou o que é produzido por produtores independentes e por grupos de intervenção em canais de acesso público. Para falar de televisão, é preciso definir o corpus, ou seja, o conjunto de experiências que definem o que chamamos de televisão (MACHADO, 2000, p. 19). 
Williams (2016) apresenta a televisão como resultado de um processo de mudança social ou como elemento presente nesse contexto.

\begin{abstract}
A televisão, como qualquer outra tecnologia, torna-se disponível como um elemento ou meio em um processo de mudança que já está ocorrendo ou está prestes a ocorrer. Em contraste com o puro determinismo tecnológico, esse ponto de vista salienta outros fatores causais na mudança social. Qualquer tecnologia específica é, portanto, subproduto de um processo social determinado por outras circunstâncias. Uma tecnologia só adquire status efetivo quando é utilizada para fins já contidos nesse processo social conhecido (WILLIAMS, 2016, p. 26-27).
\end{abstract}

A expansão de afiliadas e retransmissoras de televisão pelo território brasileiro permitiu, assim, o surgimento da televisão local em todos os estados brasileiros e a criação de identidade com as cinco regiões do país (BAZI, 2016). Isso acontece na fase que Mattos (2010) identifica como populista, entre 1964 e 1975. Um período em que a televisão se tornou mais acessível para os brasileiros, graças ao processo de industrialização vivenciado pelo país naquela época.

No interior do país, em especial do nordeste brasileiro, a televisão se torna um elemento de inclusão e integração com o restante do Brasil. "No que se refere à sociedade rural, a televisão é o principal meio de comunicação que atinge as imensas áreas do sertão nordestino" (LIMA, M., 2000, p. 77). A abrangência do sinal de TV fez com que o veículo tivesse não apenas um grande alcance como também uma penetração significativa entre os brasileiros, levando em consideração as dimensões continentais do país.

As facilidades de comercialização de televisores e a boa qualidade do sinal retransmitido por repetidoras locais e antenas parabólicas têm contribuído muito para a sua população nessas localidades. Tudo isso faz com que a televisão deixe de ser privilégio das sociedades de centros urbanos avançados e, a exemplo do rádio, passe a ser adquirida em maior quantidade pelas populações das periferias urbanas e das áreas rurais (TRIGUEIRO, [1999], p. 1).

Fernando Barbosa Lima (2007) apresenta o papel exercido pela televisão nos lares brasileiros: "Para as pessoas mais pobres e menos instruídas, gente do interior ou das capitais que não sabe ler nem escrever, mas sabe ligar um aparelho de TV, essa poderosa máquina representa o personagem mais importante da casa e da família” (LIMA, F., 2007, p. 21).

Esse fascínio dos brasileiros tem explicações que vão além da mistura de imagem e som, que juntos despertam a emoção e o interesse dos brasileiros pelo que está sendo 
veiculado. Rezende (2000) explica porque a TV no Brasil não é apenas mais um veículo do sistema nacional de comunicação:

\begin{abstract}
Vários fatores contribuíram para que a TV se tornasse mais importante no Brasil do que em outros países: a má distribuição de renda, a concentração da propriedade de emissoras, o baixo nível educacional, o regime totalitário nas décadas de 1960 e 70, a imposição de uma homogeneidade cultural e até mesmo a alta qualidade da nossa dramaturgia (REZENDE, 2000, p. 23).
\end{abstract}

Foi nos anos de 1970 que a TV no Brasil assumiu o papel de mídia de integração nacional, a partir da ampliação das torres de transmissão e o surgimento das emissoras afiliadas às grandes redes nacionais, produzindo conteúdo local e retransmitindo a programação nacional (REZENDE, 2000). A tecnologia a cores chegou ao mercado televisivo brasileiro no início dos anos 1970, criando uma nova forma de ver o próprio Brasil. Na época, desconhecido pela maioria da população.

\title{
A televisão nos estados nordestinos
}

O processo de expansão das emissoras pelo interior do Brasil não aconteceu da noite para o dia. Demorou a chegar à região Nordeste. Em alguns estados, uma década ou mais.

É surpreendente constatar, por exemplo, que alguns estados nordestinos só passaram a ter um canal próprio de televisão há pouco mais de 40 anos, ou seja, quase trinta anos depois de inaugurada a primeira emissora de TV brasileira, a TV Tupi de São Paulo (KNEIPP, 2017, p. 60).

As novas tecnologias apresentavam outras perspectivas e mais possibilidade para expansão dos sinais das emissoras e, consequentemente, a formação das redes, por meio do avanço tecnológico. Rezende (2000) destaca esse momento da história da televisão brasileira:

Em janeiro de 1969, o Brasil ingressava na era da comunicação espacial. As ligações por micro-ondas e as transmissões via satélite possibilitavam a integração nacional e aproximação com o restante do mundo. Torna-se, enfim, viável a formação de redes de TV (REZENDE, 2000, p. 109).

Nos estados nordestinos, o processo de afiliação ${ }^{3}$ ou implantação de novas emissoras teve início no fim da década de 1960, intensificou-se ao longo das décadas de

\footnotetext{
${ }^{3}$ Que efetiva a formação das redes de televisão.
} 
1970 e no início da década de 1980 já estava consolidada em todas as capitais da região.

O Quadro 1, sobre as emissoras pioneiras no Nordeste, ajuda a compreender isso melhor, com uma cronologia da chegada das primeiras emissoras regionais no nordeste brasileiro.

Quadro 1 - Emissoras pioneiras na região Nordeste.

\begin{tabular}{|c|c|c|c|}
\hline Estado & Primeira emissora do estado & Entrou no ar em: & Tipo \\
\hline PE & TV Jornal & 1960 & Comercial \\
\hline BA & TV Itapoan & 1960 & Comercial \\
\hline CE & TV Ceará & 1960 & Comercial \\
\hline MA & TV Difusora & 1963 & Comercial \\
\hline PB & TV Borborema & 1966 & Comercial \\
\hline SE & TV Sergipe & 1971 & Comercial \\
\hline AL & TV Gazeta & 1975 & Educativa \\
\hline RN & TV Universitária & 1972 & Comercial \\
\hline PI & TV Clube & 1972 & \\
\hline
\end{tabular}

Fonte: Elaborado pelos autores com base em informações nos sites das emissoras.

Nos primeiros anos da televisão Brasileira, nas décadas de 1950 e 1960, vimos impérios surgirem, como os Diários Associados, pertencente a Assis Chateaubriand e que já foi o maior conglomerado da imprensa brasileira (MATTOS, 1997). Mas, após crises financeiras e problemas de pagamento de pessoal - agravados após a morte do fundador Assis Chateaubriand, em 1968 -,o Governo Federal agiu para interromper a continuação da Rede Tupi, cassando a concessão de todas as emissoras que a compunham.

O Diário Oficial da União do dia 17 de julho de 1980 trouxe um ato presidencial, considerando peremptas as concessões de sete emissoras associadas: as TVs Tupi do Rio de Janeiro e de São Paulo, a TV Itacolomi de Belo Horizonte, a TV Marajoara de Belém, a TV Rádio Clube do Recife, a TV Piratini de Porto Alegre e a TV Ceará de Fortaleza, sendo cada estação pioneira em seus respectivos Estados (CUNHA, 2009, p.,10-11).

Antes, em 1965, a TV Globo foi fundada pelo jornalista e empresário Roberto Marinho. Em pouco tempo, com a crise financeira e posteriores cassações das concessões da TV Tupi, o sistema de emissoras da Globo conquistou a hegemonia da mídia televisiva 
brasileira (CUNHA, 2009). Em 2019, a Rede Globo possuía 123 emissoras, sendo 118 afiliadas e cinco geradoras próprias nos estados do Rio de Janeiro, São Paulo, Brasília, Minas Gerais e Pernambuco. Essas televisões são responsáveis pela regionalização da programação e produção de conteúdo local (REDE GLOBO, 2019).

Mas todo esse crescimento não foi à toa, foi bem planejado e estabelecido como meta. De acordo com BAZI (2001), a TV Globo entrou na década de 1970 com o objetivo de regionalizar a programação e conquistar mais audiência. A produção da emissora se concentrava no Rio de Janeiro e São Paulo.

Algumas capitais nordestinas, como João Pessoa e Natal, ainda não possuíam emissoras locais para gerar conteúdo e retransmitir o sinal da emissora carioca. Pensando justamente em se instalar em locais onde ainda não tinha estrutura própria ou afiliada, a Globo estabeleceu a meta de ampliar a cobertura geográfica com a criação de um grande sistema de afiliadas. Como explica Bazi (2001):

A Rede Globo tinha como meta regionalizar sua programação depois de se fortalecer nas capitais brasileiras. Foi, então, na década de 80 , que o projeto de regionalização ganhou força com a implantação, em seu organograma, de um setor específico para atender as suas afiliadas: a CGAE- Central Globo de Afiliadas e Expansão - responsável por viabilizar as emissoras locais em todas as necessidades como: programação, engenharia e jornalismo (BAZI, 2001, p. 4).

Para manter o padrão de qualidade, logo no início de criação de cada emissora afiliada, profissionais da TV Globo eram enviados para os estados, onde realizavam treinamento com os jornalistas e equipe técnica (JÚNIOR, 2014). Foi assim que aconteceu na fundação da TV Cabugi, no Rio Grande do Norte, em 1987.

Vieram editores de texto e imagem, produtores e repórteres para profissionalizar a equipe que estava sendo formada. Eles participavam diretamente do que estava sendo produzido, a fim de propor melhorias, ensinar novas técnicas de produção, indicar mudanças necessárias nas reportagens e explicar os conceitos do jornalismo praticado pela Globo (JÜNIOR, 2014, p. 28).

Antes da implantação das emissoras locais em todas as capitais nordestinas, a programação das grandes redes nacionais chegava aos estados menores apenas por meio 
de repetidoras de outras cidades, como Recife e Fortaleza, no caso do Rio Grande do Norte, que é o objeto deste estudo. ${ }^{4}$

\begin{abstract}
A dimensão continental do Brasil, a ausência de uma política governamental de comunicação igualitária para todo o país e o descompasso entre a visão empresarial regional e as possibilidades do novo veículo, as dificuldades de infraestrutura, inclusive no quesito eletrificação, estão entre os fatores que contribuíram para um cenário de diferenças e contradições no país, quando consideramos as instalações das emissoras de televisão no território brasileiro (KNEIPP, 2017, p. 60).
\end{abstract}

Ainda citando o exemplo da Rede Globo, a instalação das geradoras próprias em áreas estratégicas para distribuir o sinal da emissora carioca pelo país também comprova esse atraso do Nordeste em relação aos demais estados. A TV Globo Nordeste, hoje responsável pelo gerenciamento operacional das emissoras da região e do conteúdo produzido por elas, foi a última a ser criada e construída, na cidade do Recife, em Pernambuco, em 1972.

O objetivo dessa regionalização da programação também era criar uma identificação maior com os telespectadores, levando até eles as notícias que afetam diretamente seu cotidiano. Hall (2003) ajuda a entender que o processo de criação de identidades não acontece de uma forma única e fechada. É algo aberto e heterogêneo.

\begin{abstract}
Embora as estruturas de produção da televisão originem os discursos televisivos, elas não constituem um sistema fechado. Elas tiram assuntos, tratamentos, agendas, eventos, equipes, imagens da audiência, "definições da situação" de outras fontes e outras formações discursivas dentro da estrutura sociocultural e política mais ampla da qual são uma parte diferenciada (HALL, 2003, p. 389).
\end{abstract}

Essa proximidade com público se daria tanto pelo lado geográfico quanto pelo cultural. Afinal, a TV local consegue mostrar para o telespectador a sua própria cultura. E nesse sistema de rede de afiliadas, a emissora nacional é que define como, quando e para quem a programação local será direcionada. Em grande parte, levando em consideração interesses políticos ou mercadológicos, que contribuem para a manutenção do sistema atual de produção, veiculação e recepção do conteúdo televisivo (BAZI, 2001).

\footnotetext{
${ }^{4}$ Kneipp (2017, p. 61) registra que "esses sinais das repetidoras nem sempre eram de qualidade, na verdade, alguns apresentavam qualidade técnica bastante comprometida: 'chuviscos', fantasmas nas imagens e falhas no áudio estavam entre os problemas enfrentados".
} 


\section{A TV no RN}

No Rio Grande do Norte, a televisão chegou apenas em 1972, para fins educativos, visando à transmissão das aulas do Projeto Satélite Avançado de Comunicação Interdisciplinar (SACI), que levava ensino básico à distância nas escolas da Rede Estadual de Educação. No início, a TV Universitária (TVU) era ligada ao Instituto Nacional de Pesquisas Espaciais (INPE). Durante 15 anos, a TVU foi a única emissora de TV do estado, com programação local (HISTÓRICO...., [2017]).

Apenas em 1987 é que a primeira emissora comercial se instalou no estado. Foi a TV Ponta Negra, afiliada ao Sistema Brasileiro de Televisão (SBT), fundada pelo exsenador Carlos Alberto de Sousa. No mesmo ano surgiram a TV Cabugi, afiliada à TV Globo e fundada pelo ex-senador Aluísio Alves, e a TV Tropical, afiliada à Record TV. A Record foi fundada pelo ex-governador Tarcísio Maia e atualmente é comandada pelo filho dele, o senador José Agripino Maia. A quinta emissora comercial a ser instalada no estado foi a TV Potengi, em 1990, fundada pelo ex-senador Geraldo Melo. Após passar por uma grande crise financeira, foi vendida para a TV Bandeirantes e atualmente se chama Band Natal (KNEIPP, 2017).

Em 2019, o Rio Grande do Norte possui 12 emissoras de televisão em funcionamento, que transmitem em sinal aberto. É importante destacar que a primeira emissora de televisão chegou a terras potiguares somente 22 anos depois de ser inaugurada a primeira estação de TV do país. Antes, a programação das grandes redes chegava ao Rio Grande do Norte apenas por meio da repetição do sinal vindo de cidades próximas como Recife e Fortaleza.

O surgimento das emissoras comerciais no Rio Grande do Norte aconteceu no período da história do Brasil em que mais foram outorgadas concessões de rádio e televisão. Segundo um levantamento feito por Motter (1994), a maioria das concessões foi liberada durante o governo Sarney para políticos, ocupantes de cargos eletivos no Congresso Nacional, durante a aprovação da nova Constituição Federal.

De fato, a partir de janeiro de 1988, quando a Constituinte entrou no período mais crítico, com a votação em plenária do Projeto de Constituição, observouse um expressivo acréscimo nas concessões de canais de rádio e televisão. Das 1.028 concessões outorgadas pelo governo Sarney até a promulgação da nova Constituição, 539 (52\%) foram distribuídas nos últimos nove meses da Constituinte, precisamente de janeiro a outubro de 1988 (MOTTER, 1994, p. 92). 
Ao analisar, por exemplo, a formação da Rede Globo, um ponto a ser observado é a concentração das emissoras nas mãos de poucos grupos, tanto econômicos quanto políticos. Principalmente políticos. Atualmente, em 2019, são 123 emissoras pertencentes a 29 grupos de comunicação. Desse total, cinco são geradoras próprias da TV Globo, instaladas em cidades estratégicas para a produção de conteúdo, distribuição de sinal e comercialização dos espaços publicitários (REDE GLOBO, 2019).

Quando o foco do estudo é a região nordestina, constatamos que são 24 emissoras, pertencentes a 11 grupos de comunicação. Apenas uma delas é emissora própria da TV Globo, como observamos no Quadro2, com informações sobre os grupos proprietários das emissoras da Rede Globo nos estados nordestinos.

Quadro 2 - Grupos proprietários das emissoras da Rede Globo nos estados nordestinos.

\begin{tabular}{|c|c|c|c|}
\hline ESTADO & EMISSORA & GRUPO & FUNDADOR \\
\hline BA & 6 & Bahia & José Sarney \\
\hline MA & 5 & Mirante Carlos Magalhães \\
\hline PB & 2 & Paraíba & José Carlos da Silva Júnior \\
\hline CE & 2 & Verdes Mares & Aluízio Alves \\
\hline RN & 2 & Inter TV & Valter Alencar \\
\hline PI & 2 & Clube & Naírson Menezes \\
\hline SE & 1 & Sergipe & Arnon de Mello \\
\hline AL & 1 & Gazeta & Roberto Marinho \\
\hline PE & 1 & Globo & Inocêncio de Oliveira \\
\hline PE & 1 & Asa Branca & Osvaldo Coelho \\
\hline PE & 1 & Grande Rio & \\
\hline
\end{tabular}

Fonte: Elaborado pelos autores com base no mapa de cobertura da TV Globo (REDE GLOBO, 2019).

Maria Érica de Oliveira Lima (2001) explica como funciona essa concentração de várias empresas nas mãos de alguns grupos empresariais, especialmente nos estados nordestinos.

O controle sobre os meios de comunicação de massa se torna bem mais evidente, quando verificamos que os nossos veículos de massa se constituem, 
essencialmente, em empresas vinculadas à iniciativa privada, cuja propriedade está concentrada nas mãos de uns poucos grupos (familiares), e do Estado, que apesar de tudo, também possui alguns veículos de mídia impressa e eletrônica (LIMA, M., 2001, p. 3).

Bourdieu (1997) explica que na busca por audiência, a televisão expõe não só as diferentes esferas de produção cultural como também a política e a democracia a um grande perigo. Segundo o autor (1997, p. 13), o veículo espera que aquilo "que poderia ter se tornado um extraordinário instrumento de democracia direta não se converta em instrumento de opressão simbólica”. Portanto, a busca por resultados e audiência tem sido determinante na forma de se produzir TV no Brasil e, consequentemente, no conteúdo veiculado para os telespectadores.

Voltando à trajetória no Rio Grande do Norte, em 2006, a TV Cabugi foi vendida para o grupo Inter TV, do empresário Fernando Camargo. Hoje, a rede possui sete emissoras espalhadas pelos estados do Rio Grande do Norte, Minas Gerais e Rio de Janeiro. O mesmo aconteceu com a TV Ponta Negra, vendida para o Grupo Opinião de Comunicação, que possui emissoras nos estados da Paraíba, Pernambuco e Alagoas.

A exemplo de outras redes de comunicação, como a Rede Amazônica (Acre, Roraima, Rondônia, Amapá e Amazonas), a Rede Anhanguera (Goiás e Tocantins), a Inter TV não se concentra apenas em um estado. No caso dela, também está presente em regiões diferentes.

\begin{abstract}
A relação entre os grupos de mídia de mercados regionais, como o do Nordeste brasileiro, e os grupos de amplitude nacional vai além das associações para atender aos interesses regionais das grandes empresas. As empresas locais, basicamente de constituição familiar, como os Sarney, Magalhães, Franco, Alves, Collor de Melo, Jereissati, Lobão, Oliveira, Santos, Paes Mendonça e outras, não querem ser tratadas como simples filiais ou representantes. Se comportam em relação aos grupos nacionais na busca de parcerias, não de dependência. O que buscam é uma margem de manobras suficiente que lhes permita dominar os mercados regionais, tendo como parceiros - mas não como matriz ou modelo - um ou mais dos grandes grupos de comunicações. Trata-se de uma negação subalterna (FADUL; REBOUÇAS, 2005, p. 2).
\end{abstract}

Apesar de ter nascido com fins educativos, observa-se que a televisão potiguar, em sua maioria, segue o modelo comercial. Uma característica que segue a mesma linha do sistema televisivo brasileiro. Segundo MATTOS (1997, p. 125), "ao contrário da TV europeia, baseada no modelo estatal e que nos primeiros anos de vida foi popular, a TV brasileira ancorada no setor privado e com influências no modelo norte-americano, no 
período de 1955 a 1964 era prioridade da elite, já que poucos dispunham de um aparelho receptor".

\section{Considerações finais}

Ao analisar a trajetória de implantação das emissoras na região nordeste do Brasil, buscou-se verificar o contexto histórico em que isso aconteceu, as práticas sociais da época e a influência política que alguns grupos exerceram e ainda exercem na radiodifusão brasileira. Além disso, pôde-se observar como se deu, de certa forma, o processo de regionalização da televisão nos estados nordestinos de maneira geral, e, mais especificamente, no Rio Grande do Norte, que foi o foco específico da pesquisa.

A chegada mais tardia das emissoras de televisão ao nordeste, quando comparada com outras regiões do país, fica clara ao observar o processo de implantação das redes de TV. Como, por exemplo, no processo de formação da maior rede de mídia do Brasil, a Rede Globo. Nesse caso, foi identificado, no decorrer da pesquisa, que houve uma atenção maior aos outros grandes centros, em detrimento das capitais nordestinas.

Considerando o contexto histórico do país, foi possível perceber o papel do governo Sarney e a distribuição de licenças de TV aos aliados políticos para que as redes de televisão pudessem estar presentes em todas as capitais nordestinas. O que revela, desta forma, o critério político de distribuição de concessões que fomentou a implantação da maior parte das emissoras de televisão comercial do Rio Grande do Norte, caracterizando uma espécie de coronelismo eletrônico, "prática inerente a mídia brasileira, qual seja, a utilização das concessões de emissoras de rádio e televisão como moeda de barganha política" (PIERANTI, 2008, p. 1).

O presente estudo permitiu, em parte, evidenciar aspectos importantes para compreender um pouco mais a trajetória da televisão na região nordestina, em especial nas capitais, como as primeiras emissoras da região, os grupos dominantes e o período de instalação das emissoras.

Considerou-se, com esta pesquisa, que em algumas capitais, como o exemplo pontual do Rio Grande do Norte, as emissoras de conteúdo local e regional chegaram mais tarde. Foram quase 40 anos depois da implantação da primeira emissora de televisão no Brasil. Isso se deu porque a região era geograficamente distante dos grandes centros do país (localizados na região sudeste), as condições técnicas para a efetivação de emissoras eram onerosas, e as bases comerciais para o funcionamento e manutenção comercial também não estavam estabelecidas. 


\section{Referências}

BAZI, Rogério Eduardo Rodrigues. Depois da TV digital: o telejornalismo e as rotinas produtivas em uma emissora regional. Revista Brasileira de Ensino de Jornalismo, Campinas, v. 6, n. 18, p. 18-30, jan./jun. 2016. Disponível em:

http://www.fnpj.org.br/rebej/ojs/index.php/rebej/article/view/174/108. Acesso em: 4 abr. 2019.

BAZI, Rogério Eduardo Rodrigues. TV regional: trajetória e perspectivas. Campinas: Alínea, 2001.

BOURDIEU, Pierre. Sobre a televisão: seguido de A influência do jornalismo e Os jogos olímpicos. Rio de Janeiro: Jorge Zahar, 1997.

BRASIL. Presidência da República. Secretaria de Comunicação Social. Pesquisa Brasileira de Mídia 2016: hábitos de consumo de mídia pela população brasileira. Brasília: Secom, 2016. Disponível em: http://www.secom.gov.br/atuacao/pesquisa/listade-pesquisas-quantitativas-e-qualitativas-de-contratos-atuais/pesquisa-brasileira-demidia-pbm-2016-1.pdf/view. Acesso em: 15 fev. 2016.

CUNHA, Rodrigo do Espírito Santo da. Anotações sobre a história da televisão no Ceará (décadas de 1970 e 1980). In: CONGRESSO NACIONAL DE HISTÓRIA DA MÍDIA, 7., Unifor, Fortaleza, 2009. Anais [...]. Disponível em:

http://www.ufrgs.br/alcar/encontros-nacionais-1/encontros-nacionais/7o-encontro-20091/Anotacoes $\% 20$ sobre $\% 20 \mathrm{a} \% 20$ historia $\% 20 \mathrm{da} \% 20$ televisao $\% 20$ no $\% 20$ Ceara.pdf. Acesso em: 22 set. 2019.

FADUL, Anamaria; REBOUÇAS Edgard. Por uma perspectiva metodológica para os estudos dos sistemas e grupos de mídia: o caso do Nordeste brasileiro como referência. In: CONGRESSO BRASILEIRO DE CIÊNCIAS DA COMUNICAÇÃO, 28.,

Porto Alegre, 2005. Anais [...] São Paulo: Intercom, 2005. Disponível em: http://www.portcom.intercom.org.br/pdfs/5268445990675055739794035782746027309 7.pdf. Acesso em: 5 abr. 2019.

HALL, Stuart. Da diáspora: identidades e mediações culturais: Stuart Hall. Liv Sovik (org.). Belo Horizonte: Ed. UFMG; Brasília, DF: Representação da UNESCO no Brasil, 2003.

HISTÓRICO da TVU. Rio Grande do Norte: UFRN [2017]. Disponível em: http://www.tvu.ufrn.br/pagina.php?a=historia. Acesso: 11 out. 2019.

JOST, François. Seis lições sobre televisão. Porto Alegre: Sulina, 2004.

JÚNIOR, Francisco. RNTV: a notícia no ar. Rio Grande do Norte: [s.n.] 2014.

KNEIPP, Valquíria A. P. (org.). Trajetória da televisão no Rio Grande do Norte: a fase analógica. Rio Grande do Norte: Edufrn, 2017. 
LIMA, Fernando Barbosa. Nossas câmeras são seus olhos. Rio de Janeiro: Ediouro, 2007.

LIMA, Maria Érica de Oliveira. Neo-coronelismo na mídia nordestina. 2000.

Dissertação (Mestrado em Comunicação Social) - Universidade Metodista de São Paulo, São Bernardo do Campo, 2000.

LIMA, Maria Érica de Oliveira. Nordeste: o desenvolvimento para além das oligarquias. In: CONGRESSO BRASILEIRO DA COMUNICAÇÃO, 24., Campo Grande, MS, 2001. Disponível em: http://www.portcom.intercom.org.br/pdfs/1563316649573173963050331852671577516 95.pdf. Acesso em: 7 abr. 2018.

MACHADO, Arlindo. A televisão levada a sério. São Paulo: Editora Senac São Paulo, 2000.

MATTOS, Sérgio. Um perfil da TV brasileira: 40 anos de história. Salvador: Associação Brasileira de Agências de Propaganda: A Tarde, 1990. (Capítulo Bahia).

MATTOS, Sérgio. A televisão e as políticas regionais de comunicação. São Paulo: INTERCOM, 1997.

MATTOS, Sérgio. A história da televisão no Brasil: uma visão econômica, social e política. 5. ed. rev. e ampl. Petrópolis: Vozes, 2010.

MOTTER, Paulino. O uso político das concessões das emissoras de rádio e televisão no governo Sarney. Revista Comunicação \& Política. Rio de Janeiro, v. 1, n. 1, p. 89-116, ago./nov. 1994.

PIERANTI, Octavio Penna. A radiodifusão e os coronéis da mídia: uma discussão conceitual acerca do "coronelismo eletrônico". Eco/Pós, v. 11, n. 1, p. 128-145, jan./jul. 2008. Disponível em: https://revistas.ufrj.br/index.php/eco_pos/article/view/1005/945. Acesso em: 13 out. 2019.

REDE GLOBO. Negócios Globo: Brasil. 2019. Disponível em: https://negocios8.redeglobo.com.br/Paginas/regioes.aspx?r=Nordeste. Acesso em: 22 set. 2019.

REZENDE, Guilherme Jorge de. Telejornalismo no Brasil: um perfil editorial. São Paulo: Summus, 2000.

STUMPF, Ida Regina. Pesquisa bibliográfica. In: DUARTE, Jorge; BARROS, Antonio Carlos. Métodos e técnicas de pesquisa em Comunicação. São Paulo: Atlas, 2005. p. 51-61.

TRIGUEIRO, Osvaldo Meira. Globalização e identidade cultural: o impacto da televisão numa comunidade rural paraibana. [2019]. Disponível em: http://portcom.intercom.org.br/pdfs/062c5dc680eb0b76378d703462efefd8.PDF. Acesso em: 8 out. 2019. 
WILLIAMS, Raymond. Televisão: tecnologia e forma cultural. São Paulo: Bomtempo, Belo Horizonte: MG: PUC Minas, 2016.

Submetido em: $14 / 10 / 2019$

Aprovado em: 27/11/2019 